\title{
VARIEDADES
}

\section{SOBRE EL ESTANQUE DE MERCURIO DE MEDINA AZAHARA}

\author{
LUIS MOLINA \\ CSIC, Granada
}

Entre las dependencias que los autores árabes mencionan al describir Medina Azahara se halla un salón en cuyo centro se abría un estanque lleno de mercurio. Sin embargo, en el fundamental trabajo de Ana Labarta y Carmen Barceló sobre las fuentes árabes relativas a Medina Azahara ${ }^{1}$, las autoras ponen en duda que ese salón, que denominan «al-maŷlis al-badī', llamado qașr al-jiläfa», se encontrase realmente en la ciudad palatina y prefieren localizarlo en el alcázar de Córdoba. Argumentan que en este alcázar existía un salón llamado al-maŷlis al-badi', como quedaba de manifiesto en un trabajo anterior de García Gómez ${ }^{2}$, y que qașr al-jiläfa se aplica siempre al alcázar de Córdoba, de lo que deducen que las fuentes árabes yerran al situar el salón del estanque de mercurio en Medina Azahara.

A primera vista, no parece un argumento muy sólido para rectificar las informaciones concordantes de varios cronistas árabes, pues la coincidencia en el nombre de un salón en dos recintos palatinos, sobre todo cuando es un nombre tan poco significativo como al-maŷlis al-badī", («salón maravilloso» o, por conservar la traducción de García Gómez, «salón peregrino»), no tiene por qué suscitar la duda sobre la existencia simultánea de ambas estancias. Sólo un análisis pormenorizado de los textos que mencionan el estanque de mercurio podrá aclarar si la suposición de Labarta y Barceló tiene una base más sólida que la mera coincidencia de nombres.

\footnotetext{
${ }^{1}$ Labarta, A. y Barceló, C., "Las fuentes árabes sobre al-Zahrā': Estado de la cuestión", Cuadernos de Madinat al-Zahrā', I (1987), 93-106.

2 "Notas sobre la topografía cordobesa en los «Anales de al-Hakam II" por 'Īsà al-Rāzī”, Al-Andalus XXX (1965), 319-379. Sin embargo, del texto de García Gómez se desprende que la única fuente en la que halla documentada la existencia del Salón Peregrino (así traduce él al-mâylis al-badī') es el Naf̣h al-țīb, en un párrafo que, como se verá más adelante, es idéntico al que reproduce Ibn Gālib, pero referido a Medina Azahara.
}

Al-Qanțara XXV, 2 (2004) 329-333 
Contamos con un texto fundamental sobre el estanque de mercurio en Medina Azahara, del que poseemos tres testimonios: se trata de la descripción que del mismo hace al-Zuhrī (s. VI/XII) en su Kitāb al-ŶY $r a \bar{f} i y y a^{3}$, texto que es reproducido en el anónimo Dikr biläd al-Andalus (s. VIII-IX/XIV-XV) ${ }^{4}$, de donde pasa al Naf̣ al-țîb de al-Maqqarī (s. XI/XVII) ${ }^{5}$. Las relaciones entre estas tres obras están claras desde la publicación de la segunda de ellas: el compilador del Dikr tuvo a su disposición un fragmento del Kitāb al-ŶYa räfiyya de al-Zuhrī, fragmento que incluyó en su totalidad en su crónica, mientras que al-Maqqarī reproduce largos pasajes del Dikr, especialmente de los capítulos dedicados a la descripción de Córdoba ${ }^{6}$. Pero si esta cadena de transmisión historiográfica está perfectamente establecida y es incuestionable en sus líneas generales, no es menos cierto que un análisis minucioso del pasaje que nos ocupa tal vez aporte algún matiz que arroje luz sobre algún aspecto concreto, como puede ser el de la localización de este salón.

El texto original de al-Zuhrī reza así al describir el salón que denomina al-Qalbaq ${ }^{7}$ :

Su techumbre era de oro y grueso y puro cristal, lo mismo que sus muros; sus tejas eran de oro y plata. En el centro tenía un estanque lleno de mercurio y a cada lado del salón se abrían ocho puertas, formadas por arcos de marfil y ébano que reposaban en columnas de cristal ${ }^{8}$ coloreado, de forma que los rayos del sol, al entrar por esas puertas, se reflejaban en su techumbre y en sus paredes, produciéndose entonces una luz resplandeciente y cegadora ${ }^{9}$. Cuando al-Nāṣir quería asustar a los presentes o recibía la visita de algún embajador, hacía un gesto a sus esclavos y éstos removían ese mercurio, con lo que el salón se llenaba de sobrecogedores fulgores semejantes al resplandor del rayo, creando a los que allí se

${ }^{3}$ Hadj-Sadok, M, "Kitāb al-Dja'rāfiyya. Mappemonde du calife al-Ma'mūn reproduite par Fazārī (III $/ \mathrm{IX}^{\mathrm{e}} \mathrm{s}$.) rééditée et commentée par Zuhrī (VI' $/ \mathrm{XII}^{\mathrm{e}} \mathrm{s}$.)", Bulletin d'Études Orientales XXI (1968), 7-312; el texto se halla en las páginas 220-221, § 228.

${ }^{4}$ Una descripción anónima de al-Andalus, ed. y trad. Luis Molina, Madrid, 1983, 2 v., I, 164, II, 174.

5 Ed. Ihsān 'Abbās, Beyrut, 1968, 8 v., I, 527.

${ }^{6}$ Dikr, II, 303 y 309.

7 Variantes en otros manuscritos: al-Qalīq, al-Qaylaq, al-Qaylīq.

8 Variantes: "mármol", "mármol zaragozano".

9 Literalmente, "que les arrebata (ya'jud) la vista". Alusión a Corán, II, 20. En uno de los manuscritos: "que casi les arrebata (yajtaf) la vista", que recupera el término empleado en el Corán. Los otros manuscritos emplean ya'jud en lugar del coránico yajtaf, aunque el sentido es el mismo, como se comprueba por la definición que da el Tây al-'arūs de al-Zubaydī del término jātif: "relámpago que arrebata (ya 'jud̆) la vista". 
hallaban la impresión de que el salón giraba en el aire mientras el mercurio seguía en movimiento. Algunos dicen que el salón giraba para estar enfrentado al sol, siguiendo su curso, mientras que otros afirman que estaba fijo, sin moverse alrededor del estanque ${ }^{10}$. Ningún otro soberano, ni entre los infieles ni en el Islam, había construido antes nada parecido, pero a él le fue posible hacerlo por la abundancia de mercurio que allí tenían.

Mientras que en el $D i k r$ se describe el Salón del Califato (en negrita las diferencias con respecto a la versión de al-Zuhrī):

Su techumbre era de oro y mármol ${ }^{11}$ de grueso volumen y color puro, en sus distintos tonos, lo mismo que sus muros. En el centro de este salón peregrino (hāda al-mâylis al-badī') se hallaba la perla única que le regaló el rey de Constantinopla. Las tejas de este salón eran de oro y plata. En el centro tenía un gran estanque lleno de mercurio y a cada lado del salón se abrían ocho puertas, formadas por arcos de marfil y ébano con incrustaciones de oro y diversos tipos de piedras preciosas, que reposaban en columnas de mármol coloreado y cristal de roca (ballūr) puro, de forma que los rayos del sol, al entrar por esas puertas, se reflejaban en su techumbre y en sus paredes, produciéndose entonces una luz cegadora. Cuando el soberano quería asustar a los presentes, hacía un gesto a uno de sus esclavos y éste removía ese mercurio, con lo que el salón se llenaba de sobrecogedores fulgores semejantes al resplandor del rayo, creando a los que allí se hallaban la impresión de que el salón giraba mientras el mercurio seguía en movimiento. Algunos dicen que el salón giraba para estar enfrentado al sol, mientras que otros afirman que estaba fijo alrededor del estanque. Ningún otro soberano, ni entre los infieles ni en el Islam, había construido antes nada parecido, pero a él le fue posible hacerlo por la abundancia de mercurio que allí tenía.

Al-Maqqarī, por su parte, reproduce con total fidelidad la versión del Dikr, sin ninguna variante reseñable ${ }^{12}$.

Vemos, por tanto, que el Dikr copia casi al pie de la letra el texto de al-Zuhrī, pero introduce algunas palabras y frases que no se hallan en el original. La mayoría son simples variantes o amplificaciones re-

10 Seguimos la lectura de los manuscritos lām y ŷim, que da sentido a la frase.

11 Paleográficamente la confusión entre cristal (zuŷāy) y mármol (rujām) es perfectamente explicable. Recuérdese que algunos manuscritos del Kitāb al-Y Ya ${ }^{c}$ räfiyya leen también "mármol".

12 Existe otra versión, coincidente en términos generales con ésta, aunque textualmente no tenga muchos puntos de contacto. Se trata de un pasaje del Siyar a läm alnubalä' de al-Dahabī (s. VIII/XIV) en el que leemos (VIII, 267): "Edificó un salón que dominaba los jardines y cuyas columnas forró de oro incrustado de jacintos, esmeraldas y perlas, pavimentándolo con mármol de colores; delante de él construyó una pila circular que llenó de mercurio, en el que se reflejaba la luz hacia el salón.” 
tóricas (en algún caso habría que calificarlas de mejoras decorativas), pero hay un dato nuevo que en modo alguno puede ser atribuido al deseo del compilador del Dikr de enriquecer más aún el lujo del salón. Aunque, para ser más exactos, habría que reconocer que también en este caso es ese loable deseo el que provoca la inclusión de la noticia a la que nos referimos, sólo que esta vez no recurre a su fértil imaginación y a su variado léxico para redecorar por su cuenta el ya de por sí recargado y ostentoso salón, añadiéndole oros, piedras preciosas y nobilísimos materiales. Rebuscando por otros lugares de la geografía literaria de Medina Azahara, nuestro entusiasta compilador se ha topado con una pieza única que, de acuerdo con sus criterios decorativos, estima que no desentonaría lo más mínimo en el ambiente de ese salón: la perla regalada a ${ }^{\mathrm{c}} \mathrm{Abd}$ al-Raḥmān III por el emperador bizantino, perla que, aunque no dispongamos de una descripción exacta, suponemos de tamaño considerable y de perfección inmaculada. Su único fallo al trasladar la nacarada esfera a este salón fue colocarla en el centro de la habitación, centro en el que ya se encontraba el estanque de mercurio. Pero, como decimos, esta perla no se formó en la cabeza del autor del Dikr, sino que halló el dato en otra fuente distinta de al-Zuhrī y no dudó en insertarlo dentro del relato que había tomado de éste para realzar el esplendor del salón.

La noticia de la perla, en efecto, la podemos hallar en un pasaje que, posiblemente originario de Ibn Hayyān, reproducen en idénticos términos Ibn Gālib (s. VI/XII) ${ }^{13}$, Ibn ' ${ }^{\mathrm{C}} \mathrm{d}$ ārī (s. VIII/XIV) ${ }^{14} \mathrm{y}$ al-Maqqarī ${ }^{15}$ :

En cuanto a la perla única que estaba colocada en el Salón Peregrino (al-maŷlis al-badī ), procedía de un regalo que le hizo León, señor de Constantinopla ${ }^{16}$.

Lo que nos interesa retener de todo esto es un dato aparentemente menor: la mención de que la perla se hallaba en el Salón Peregrino; y

\footnotetext{
13 'Abd al-Badī, L., "Nașs andalusĩ ŷadīd: qiț'a min "Kitāb Farhat al-anfus" li-bn Gālib", Maŷallat Ma'had al-Majtūtāt al- 'arabiyya I (1955), 282-310.

${ }_{14}$ Al-Bayān al-mugrib, ed. Colin y Lévi-Provençal, Leiden, 1948-51, II, 232.

15 Nafh, I, 541.

16 Ésta es la versión de Ibn Gālib (p. 301), mientras que Ibn 'Iḍārī y al-Maqqarī finalizan así la frase: "regalo que envió a al-Nāsir, junto con otros muchos magníficos, el césar griego (Maqqari: "de los griegos"), señor de Constantinopla". El emperador bizantino León VI falleció en el 912, unos meses antes de que 'Abd al-Raḥmān al-Nāṣir, el constructor de Medina Azahara, ocupara el trono.
} 
nos interesa retenerlo porque, si volvemos sobre la descripción original del salón en el que se hallaba el estanque de mercurio, es decir, la de al-Zuhrī, comprobaremos que en ningún momento se identifica esa estancia con el Salón Peregrino, que ni siquiera es mencionado. El Salón Peregrino aparece únicamente en la versión del Dikr porque su autor introduce la frase referida a la perla, aunque altera levísimamente la redacción, de forma que lo que en su fuente era «en el Salón Peregrino» se convierte en "este salón peregrino».

En conclusión, el salón en el que se ubicaba el estanque de mercurio no llevaba el nombre de Salón Peregrino y, por tanto, no hay ninguna razón para argumentar, basándose en la suposición de que había un Salón Peregrino en el Alcázar de Córdoba ${ }^{17}$, que el salón del estanque de mercurio tenía que hallarse en el palacio de la capital en lugar de en Medina Azahara. Las fuentes son claras al respecto: el estanque de mercurio estaba en una estancia llamada por al-Zuhrī al-Qalbaq (o al-Qaliq/al-Qaylaq/al-Qayliqq), por el Dikr, Salón del Califato, y por al-Maqqarī, Alcázar del Califato, y dicha estancia formaba parte de Medina Azahara. El Salón Peregrino, por su parte, era el lugar donde había sido colocada la perla regalada por el emperador bizantino y, a pesar de la poca claridad de algunas fuentes, parece que se hallaba también en Medina Azahara. Fue el compilador del Dikr, siempre dado a la exageración, a la fantasía y a la afición por lo maravilloso, quien mezcló los datos de los dos salones. Desde un punto de vista historiográfico es un hecho incuestionable; otra cosa es que la realidad fuera muy distinta de lo que nos pintan los textos y que nos encontremos ante un relato fabuloso o legendario, producto de la imaginación desbordante de algún cronista $\mathrm{o}$, tal vez, de la magnificación de algún pequeño artificio de mercurio que podía decorar cualquier salón del palacio califal.

17 Algo que, por otra parte, es muy dudoso, pues Ibn Gālib introduce la frase sobre la perla y el Salón Peregrino en su descripción de Medina Azahara, mientras que Ibn 'Iḍārī y al-Maqqarī no dejan muy claro dónde se hallaba. 